\title{
A Study on Wind Smoothing Control by Using Short-term Average Value through Detecting Wind Power Fluctuation Rate
}

\author{
Sang Heon Chae ${ }^{1}$ and Eel-Hwan Kim ${ }^{1}$ \\ ${ }^{1}$ Department of Electrical Engineering \\ Jeju National University \\ Jeju-si, Jeju Special Self-Governing Province, 63243, Republic of Korea \\ Phone/Fax number: +82 64 7543678, e-mail: chae@jejunu.ac.kr, ehkim@jejunu.ac.kr
}

\begin{abstract}
In order to increase grid stability, there are some methods to reduce wind power fluctuation by using energy storage system (ESS). Operating time of ESS will determine its losses and the lifetime of batteries. From this point, this paper proposes a wind power smoothing control by calculating shortterm average value of wind power. In this case, the operation of ESS will be decided through detecting wind fluctuation rate during 60 seconds. It means that the ESS will not operate at small fluctuation of wind power which does not affect the grid stability. The effectiveness of proposed method will be verified by comparing the conventional method with the proposed method. The wind power data were measured by power quality analysis device from $15 \mathrm{MW}$ wind farm in Jeju Island located in South of Korea peninsula. The simulation results are carried out by using Matlab program.
\end{abstract}

Key words: Energy storage system, Ramp rate control, Wind power fluctuation, Wind farm, Wind smoothing control,

\section{Introduction}

The environmental pollution from using fossil fuels has promoted the use of renewable energy such as wind power (WP) and photovoltaic (PV). Therefore, installation of WP is sharply increasing all over the world. However, the intermittent characteristics of WP may have negative effect on grid stability, especially in weak grid [1]-[3]. Power system of Faroe Island which is not connected to Supergrid in Europe started the Husahagi project with ramp rate control in 2015. In this project, ESS will be installed at Husahagi wind farm with the rated capacity of $12 \mathrm{MW}$. The ESS consists of power conversion system with the rated capacity of $2.3 \mathrm{MW}$ and lithium ion batteries with the rated capacity of $0.7 \mathrm{MWh}$ [4].

Power system of Jeju Island, which is connected with main grid (S. Korea) by unidirectional HVDCs, also has a project similar with Faroe Island for reducing wind power fluctuation (WPF). In this project, the ESS was installed at Haengwon wind farm with the rated capacity of $3 \mathrm{MW}$ in 2016. The ESS consists of PCS with the rated capacity of $1 \mathrm{MW}$ and lithium ion batteries with the rated capacity of $0.5 \mathrm{MWh}$.

Although the ESS can reduce the WPF, the operation of ESS causes losses because of efficiency of PCS and batteries. Conventional methods for reducing the WPF such as ramp rate control and wind smoothing control (WSC) requires long time of ESS operation. Therefore, this paper proposes WSC by calculating short-term average value of WP output through detecting the WPF rate. The effectiveness of proposed method will be verified by comparing the conventional WSC with the proposed WSC. The WP output data was measured by power quality analysis device from $15 \mathrm{MW}$ wind farm in Jeju Island. The sampling time of data is one second.

\section{Wind smoothing control by low pass filter}

There are some methods for the WSC such as low pass filter (LPF), Kalman filter and moving average. This paper uses a LPF to compare with the proposed method. The WSC by LPF has a good ability to reduce the WPF. However, it has some disadvantages including requirement of large scale of ESS, delayed time of output power, long time of ESS operation and fixed smoothing time constant. The calculation for total output power of WP and ESS are expressed as [4]-[10]:

$$
\begin{aligned}
& P_{f t d_{-} t}=\frac{\tau}{\tau+t_{s}} P_{f t d_{-} t-1}+\frac{t_{s}}{\tau+t_{s}} P_{t} \\
& P_{\text {ref }}=P_{f t d_{-} t}-P_{t} \\
& P_{\text {total_t }}=P_{t}-P_{r e f}
\end{aligned}
$$

where, $P_{f t d_{-} t}$ : Low pass filtered output

$P_{t}:$ WP output

$\tau$ : Smoothing time constant

$t_{s}:$ Sampling time

$P_{\text {ref }}:$ Output power of ESS 


\section{$P_{\text {total_t } t}:$ Total output power of WP and ESS}

\section{Proposed wind smoothing control}

The WPF may have a negative effect on weak grid in accordance with grid scale. However, the small WPF can be ignored for saving losses and lifetime of ESS. In the standard of Korean government, WPF rate during 1 minute is limited by $10 \%$.

The control algorithm of proposed WSC is illustrated in Fig. 3. Firstly, WPF during 1 minute is calculated from the WP output. Secondly, if the WPF during 1 minute is over $10 \%$, the ESS will start the WSC. Thirdly, the active power reference of ESS is estimated by the short-term average value of WP. In this paper, the short-term average value is decided by 6 seconds from Figs. 4 and 5 that show the maximum output power of ESS and the WPF rate depending on the short-term average value. The high average value requires a long time of ESS operation and a high power of ESS. The small average value can causes a high WPF [11]-[12].

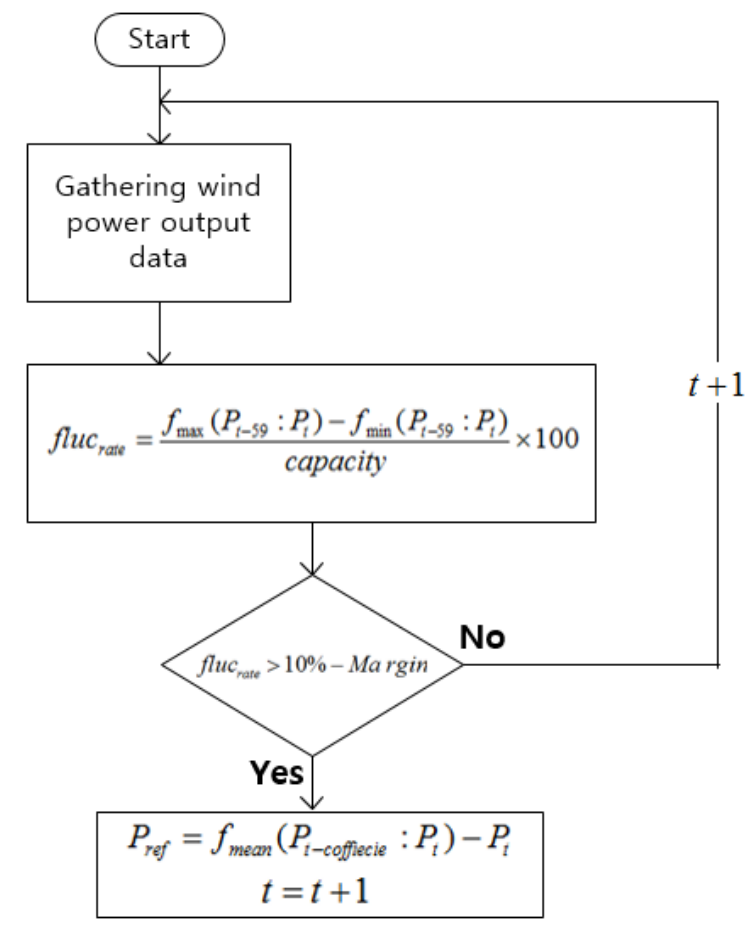

Fig. 1. Control algorithm of proposed method

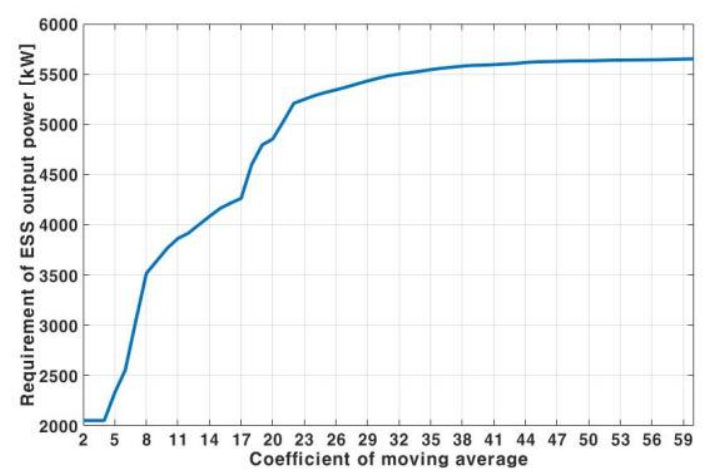

Fig. 2. Requirement of ESS output power depending on shortterm average value

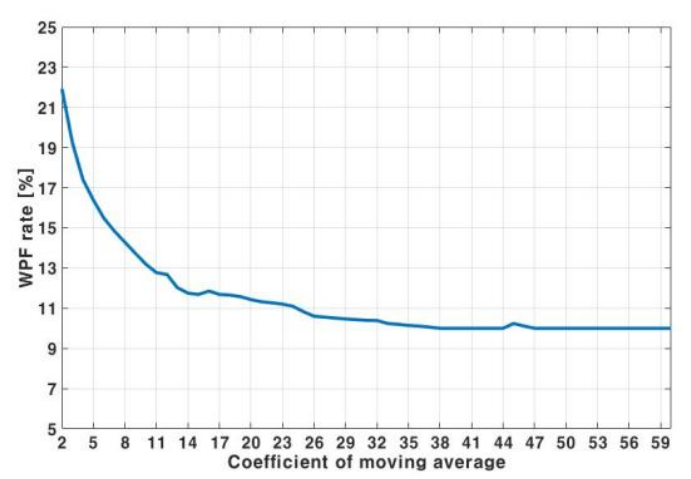

Fig. 3. WPF rate depending on short-term average value

In this case, $P_{\text {total_t } t}$ will be delayed to next sampling time because $P_{\text {ref }}$ will be estimated at $t$ th second and then it will adjust next step of WP output. The calculations of WPF during 1 minute and total output power of WP and ESS are as follows:

$$
\begin{aligned}
& \text { fluc }_{\text {rate }}=\frac{f_{\max }\left(P_{t-59}: P_{t}\right)-f_{\min }\left(P_{t-59}: P_{t}\right)}{\text { capacity }} \times 100 \text { (4) } \\
& P_{\text {ref }}=f_{\text {mean }}\left(P_{t-\text { shortterm }}: P_{t}\right)-P_{t} \\
& P_{\text {total_t } t+1}=P_{t+1}-P_{\text {ref }}
\end{aligned}
$$

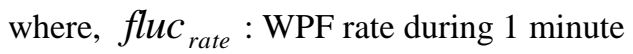

$$
f_{\max }\left(P_{t-59}: P_{t}\right) \text { : Maximum WP during } 1 \text { minute }
$$$$
f_{\text {min }}\left(P_{t-59}: P_{t}\right) \text { : Minimum WP during } 1 \text { minute }
$$$$
f_{\text {mean }}\left(P_{t-\text { shortterm }}: P_{t}\right) \text { : Short-term average of }
$$

WP

\section{Simulation results}

In order to evaluate the effectiveness of proposed WSC method, this paper compares with the conventional WSC through two different WP conditions such as normal and high WP output. The smoothing time constant of WSC by LPF is about 79 seconds that can make WPF under $10 \%$ of WP output on Feb 21th, 2015. Then the margin of fluctuation rate for proposed method is about $0.5 \%$. In actual system, the ability of WSC is limited by capacity of PCS. From this point, the output power of ESS will have a limitation for $1,500 \mathrm{~kW}$ which is $10 \%$ of wind farm capacity. In the simulation, the efficiency of PCS is assumed by $90 \%$ and the round trip efficiency of batteries is also assumed by $90 \%$.

\subsection{Normal wind power output on Feb 21th, 2015}

On Feb 21th, 2015, the WP average output was recorded by $3544.4 \mathrm{~kW}$. This capacity factor is $23.6 \%$ which is close to average value of wind farm in Jeju Island as shown in Fig. 4(a). The WPF rate during 1 minute of this day is over $25 \%$ as seen in Fig. 4(b). The WP output with the conventional and the proposed method demonstrate the ability of WSC as illustrated in Figs. 5(a) and 6(a) respectively. In this case, the WSC with LPF is more clearly. In Fig. 6(b), the ESS only 
operates during 2995 seconds. In contrary, the ESS can operate about 73150 seconds with the LPF method as shown in Fig. 5(b). It means that the charging and discharging cycles of batteries increase and the losses of ESS also increase. In the WPF rate during 1 minute with proposed method as shown in Fig. 6(c), WPF rate exceeds 371 times from $10 \%$. The WPF rate with LPF method exceeds 83 time from $10 \%$ because of the limitation of PCS as demonstrated in Fig. 5(c). Although the WPF rate with LPF method is lower than with the proposed method, the proposed method does not operate under $10 \%$ of WPF rate. Therefore, it can save the losses and lifetime of batteries. Table. 1 shows summary of simulation results.

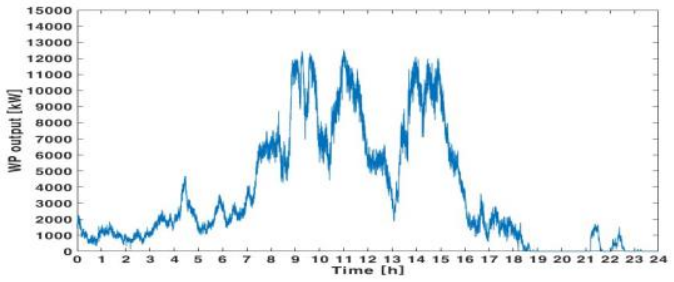

(a) WP output

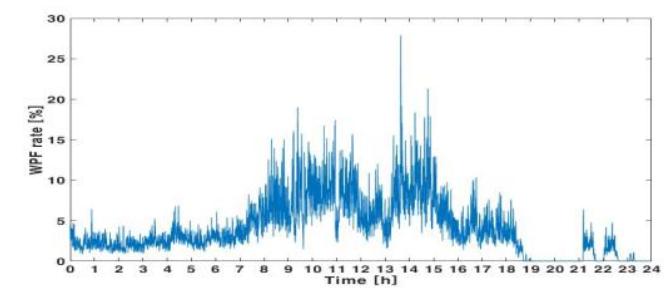

(b) WPF rate during 1 minute

Fig. 4. Simulation results without control on Feb 21th, 2015

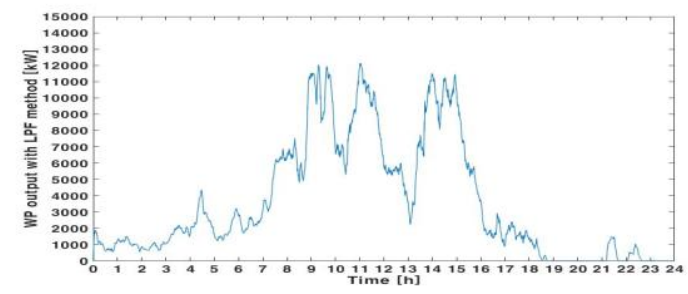

(a) WP output

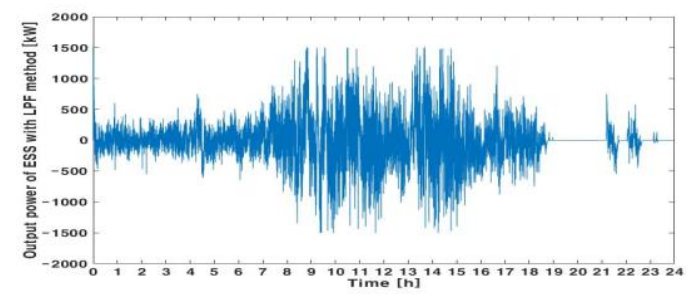

(b) Output power of ESS

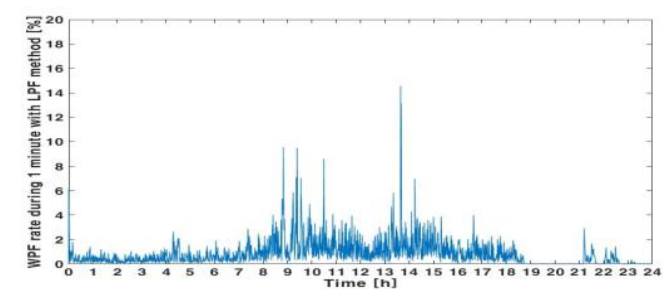

(c) WPF rate during 1 minute

Fig. 5. Simulation results with WSC by LPF method on Feb 21th, 2015

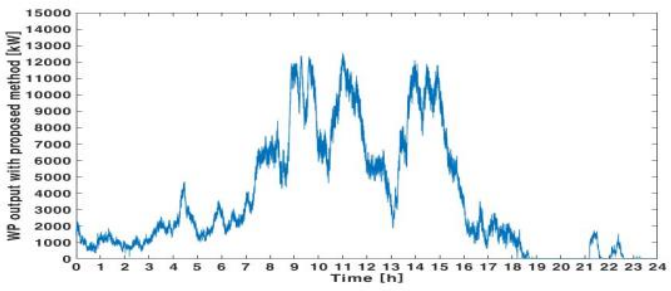

(a) WP output

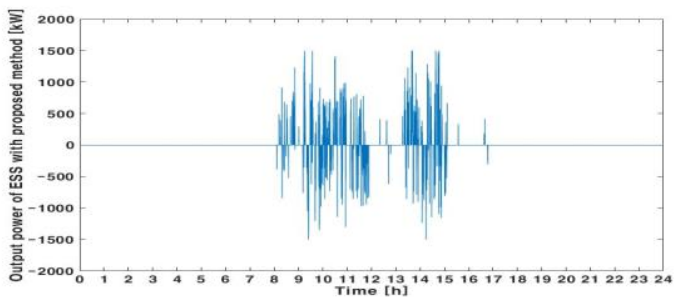

(b) Output power of ESS

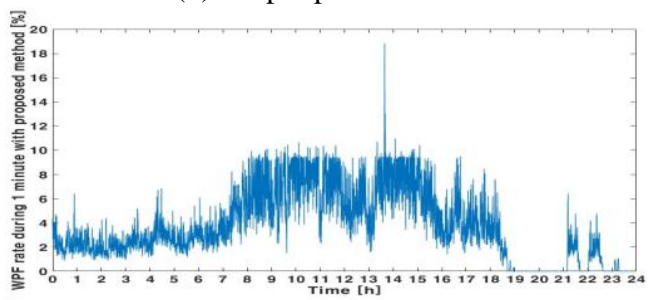

(c) WPF rate during 1 minute

Fig. 6. Simulation results with proposed method on Feb 21th, 2015

Table 1. Simulation results on Feb 21th, 2015

\begin{tabular}{|l|c|c|}
\hline \multicolumn{1}{|c|}{ Item } & $\begin{array}{c}\text { LPF } \\
\text { method }\end{array}$ & $\begin{array}{c}\text { Proposed } \\
\text { Method }\end{array}$ \\
\hline Maximum WPF rate & $18.81 \%$ & $14.57 \%$ \\
\hline Number of WPF over 10\% & 83 times & 371 times \\
\hline Operation times of ESS & $73150 \mathrm{~s}$ & $2995 \mathrm{~s}$ \\
\hline Total losses & $687.1 \mathrm{kWh}$ & $71.1 \mathrm{kWh}$ \\
\hline
\end{tabular}

\subsection{High wind power output on Mar 23th, 2015}

On Mar, 23th, 2015, the WP average output was recorded by $9612.8 \mathrm{~kW}$. This capacity factor is $64.1 \%$ which is very high value of wind farm as shown in Fig. 7(a). The WPF during 1 minute rate of this day is over than $29 \%$ as seen in Fig. 7(b). In the WP output with the conventional and the proposed methods, the LPF method can make the WP smoother than the proposed method as illustrated in Figs. 8(a) and 9(a), respectively. The ESS with the LPF method operates during 73150 seconds as shown in Fig. 8(b). However, the ESS with the proposed method only operates 13974 seconds. In WPF rate during 1 minute with the proposed method as shown in Fig. 9(c), the WPF rate exceeds 2168 times from $10 \%$. The WPF rate with the LPF method exceeds 1023 times from $10 \%$ because of the limitation of PCS. Although the WPF rate with LPF method is lower than the proposed method, it can avoid an unnecessary operation of ESS. Table. 2 shows a summary of simulation results. 


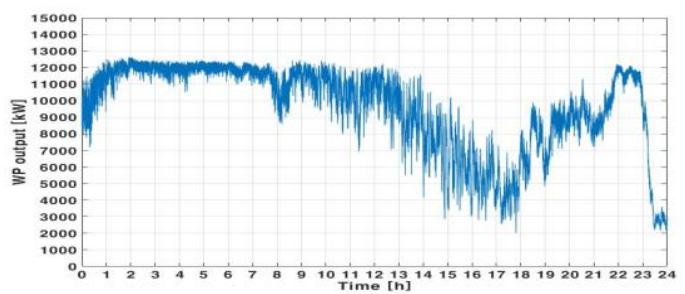

(a) WP output

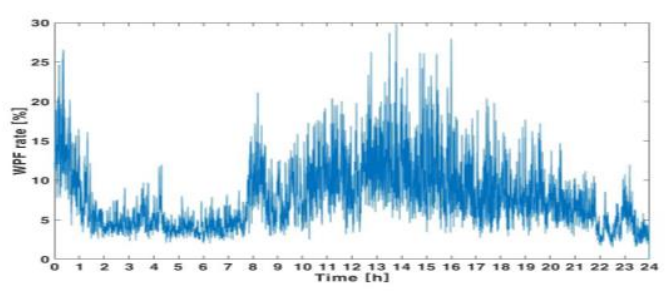

(b) WP output with proposed method in 23th,

Mar 2015

Fig. 7. Simulation results on Mar, 23th 2015 without control

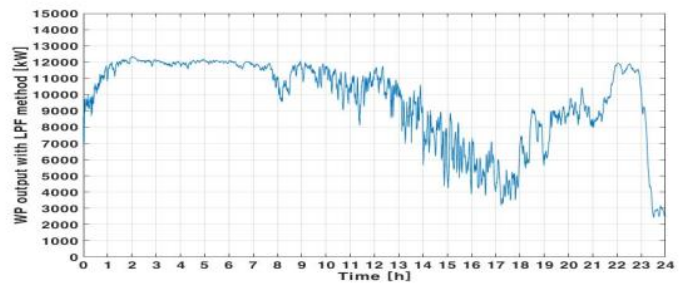

(a) WP output

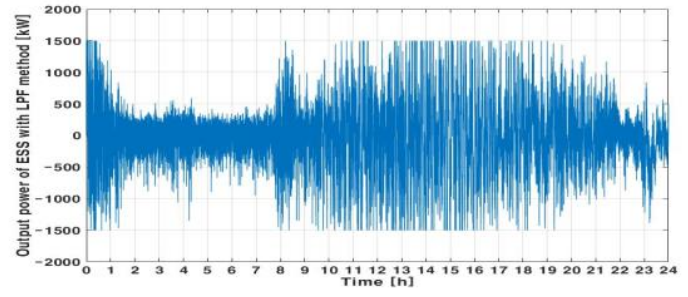

(b) Output power of ESS

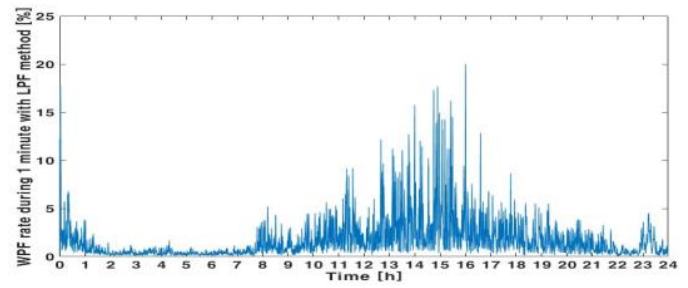

(c) WPF rate during 1 minute

Fig. 8. Simulation results on Mar, 23th 2015 with LPF method

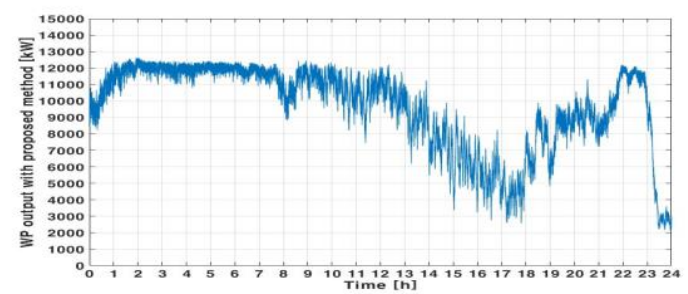

(a) WPF rate during 1 minute

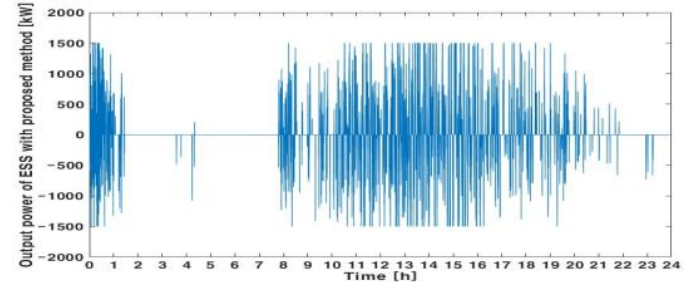

(b) Output power of ESS

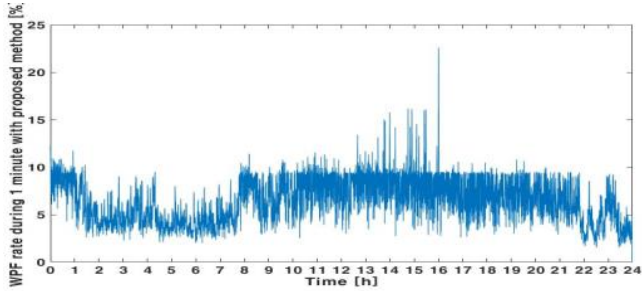

(c) WPF rate during 1 minute

Fig. 9. Simulation results on Mar, 23th 2015 with proposed method

Table 2. Simulation results on Mar, 23th 2015

\begin{tabular}{|l|c|c|}
\hline \multicolumn{1}{|c|}{ Item } & $\begin{array}{c}\text { LPF } \\
\text { method }\end{array}$ & $\begin{array}{c}\text { Proposed } \\
\text { Method }\end{array}$ \\
\hline Maximum WPF rate & $20.03 \%$ & $22.59 \%$ \\
\hline Number of WPF over 10\% & 1023 times & 2168 times \\
\hline Operation times of ESS & $86400 \mathrm{~s}$ & $13974 \mathrm{~s}$ \\
\hline Total losses & $1330.2 \mathrm{kWh}$ & $484.5 \mathrm{kWh}$ \\
\hline
\end{tabular}

\section{Conclusion}

This paper has proposed the WSC by using short-term average of WP through detecting WPF rate during 1 minute. From the simulation results, the proposed method can reduce operation times of ESS and losses. Although proposed method has little lower ability of reducing WPF rate than WSC by LPF method, the operation time and total losses of ESS are quite reduced by the proposed method. The ESS connected wind farm will save lifetime of batteries and reduce losses from proposed method.

\section{References}

[1] R. S. Bhatia, S. P. Jain, D. K. Jain, and B. Singh, "Battery Energy Storage System for Power Conditioning of Renewable Energy Sources," International Conference on Power Electronics and Drive Systems (IEEE PEDS 2005), Conference CDROM, pp. 501-506, Malaysia, 2005.

[2] Stijn Cole, Karim Karoui Til Kristian Vrana, Olav B. Fosso Jean-Baptiste Curis, Anne-Marie Denis, Chen-Ching Liu, "A EUROPEAN SUPERGRID: PRESENT STATE AND FUTURE CHALLENGES", 17th Power Systems Computation Conference, 2010.

[3] Feltes J.W, Gemmell B.D, Retzmann D, "From Smart Grid to Super Grid: Solutions with HVDC and FACTS for grid access of renewable energy sources", Power and Energy Society General Meeting, 2011.

[4] SAFT, "Saft and ENERCON's megawatt-scale energy storage system to help Faroe Islands stabilize its grid while increasing wind power usage", Press release, 2015.

[5] A. Uehara, A. Pratap, T. Goya, T. Senjyu, A. Yona, A. Urrasaki and T.Funabashi "A coordinated control method to smooth wind power fluctuations of a PMSG-based WECS "IEEE Trans. Energy Convers., vol . 26, no. 2, lune 2011.

[6] C. Abbey and G. 100s, "Short-term energy storage for wind energy application," in Proc. 40th IEEE Industry Application 
Conference, vol. 3, pp. 2035-2042, 2005.

[7] A Esmaili and A Nasiri, "Power smoothing and power ramp control for wind energy using energy storage," Energy Conversion Congress and Exposition (ECCE),pp. 922 - 927, 2011.

[8] LIN Jin, Sun Yuan-zhang, Poul Sorensen, Li Guo-jie, Li Xiong, "Frequency modeling of wind power fluctuation and the application on power systems" in Proc. Int. International Conference on Power System Technology, pp. 1 8, 2010.

[9] Changling Luo, Hadi Banakar, Baike Shen, Boon-Teck Ooi, "Strategies to Smooth Wind Power Fluctuations of Wind Turbine Generator" IEEE Transactions on Energy Conversion, vol. 22, pp. 341 349, 2007.
[10] Andrew Hamann, Gabriela Hug, "Using cascaded hydropower like a battery to firm variable wind generation", 2016 IEEE Power and Energy Society General Meeting (PESGM), 2016.

[11] Duehee Lee, Joonhyun Kim, Ross Baldick, "Stochastic Optimal Control of the Storage System to Limit Ramp Rates of Wind Power Output", IEEE Transactions on Smart Grid, Vol. 4, No. 4, pp2256-2265, 2013.

[12] Ali Esmaili, Adel Nasiri, "Power smoothing and power ramp control for wind energy using energy storage", 2011 IEEE Energy Conversion Congress and Exposition, 2011. 